\title{
Ciência circular ou circular ciência: como a pandemia de COVID-19 mudou a cara da pesquisa
}

Rubia Carolina Farias Santos (D)

O dicionário de língua portuguesa Priberam define circular como "partir de um ponto e voltar a ele por outro caminho". Ou ainda, correr de mão em mão, de boca em boca. Dinfundir-se, divulgar-se, espalhar-se. Em lógica, é argumento que já contém uma suposição do que deve ser provado e, portanto, falaz. Apesar deste significado ser em muitos casos aplicável à ciência, ${ }^{1}$ pensamos aqui em ciência circular como algo que volta a seu ponto inicial, sendo o pesquisador seu próprio público-alvo e leitor final, e em circular ciência: como levar a pesquisa para fora da academia e dos laboratórios. Dos mais de 1,5 milhão de artigos publicados anualmente, acredita-se que apenas 20 por cento daqueles citados foram realmente lidos e estima-se que um artigo médio em um periódico revisado por pares seja lido na íntegra por no máximo dez pessoas. ${ }^{2}$ Se publicações científicas mal atingem aqueles que as produzem, o que dizer do público em geral? Como alcançá-los?

Em minicurso ofertado no ABEC Meeting 2017, realizado na Pontifícia Universidade Católica do Paraná, o Prof. Ronaldo Ferreira Araújo, da Universidade Federal de Alagoas, discorreu sobre nova modalidade do marketing que busca alavancar o crescimento de produtos científicos. Uma vez que o conhecimento é um produto como outro qualquer e deve, portanto, ser divulgado, o marketing científico digital nada mais é do que aplicar conhecimento mercadológico ao fazer científico. Mas como?

O Brasil se destaca no panorama internacional do acesso aberto com grande parte dos periódicos disponibilizando seu conteúdo on-line e sem custo aos leitores, ${ }^{3}$ porém pouco se pensa na divulgação científica para públicos variados, sendo as iniciativas eventuais ou ocasionais ${ }^{4}$ e seguindo formatos tradicionais e pouco atrativos. $\mathrm{Na}$ Europa, em contrapartida, iniciativas diferenciadas têm sido criadas, como o STEAM Summer School e o Creations, ${ }^{4}$ que buscam, através do uso da criatividade e das artes, melhorar a conscientização científica e aumentar a participação de alunos nas carreiras de ciência, tecnologia, engenharia e matemática, fomentando a interdisciplinaridade. Outra abordagem interessante é o To Selfie or Not to Selfie - How Can Scientists Foster Public Trust on Instagram? Tomando como base um estudo da Universidade de Princeton, ${ }^{5}$ que concluiu que cientistas são vistos como pessoas inteligentes, mas não muito calorosas, o projeto pretende descobrir se a humanização dos cientistas através do uso do Instagram é capaz de influenciar a percepção do público e ganhar 
sua confiança. O que a princípio parece superficial e ineficaz, apoia-se em conceitos básicos da psicologia e do comportamento humano: já que o conhecimento especializado é tão essencial para a credibilidade quanto parecer confiável, é importante que a abordagem do cientista, em seu papel de comunicador, seja tanto racional quanto emocional.

Isso tornou-se bastante evidente com o surgimento da pandemia de COVID-19, em que houve um aumento do interesse púbico pela ciência e as redes sociais se mostraram uma ferramenta poderosa com a qual pesquisadores podem se comunicar de forma direta e acessível com o público não acadêmico. A pandemia, entretanto, também tornou visível algo mal compreendido pela população: o fato de que a ciência não é um todo claro e definido e que "o consenso científico é criado pela pesquisa, pelo confronto, pela tentativa de refutar afirmações e pela reprodução de resultados". 6 Seguindo o caminho contrário das redes sociais, onde rapidez é a norma, pesquisas científicas demandam tempo e, não raro, muitos erros. Para um público que desconhece este processo, e em um meio onde informação e desinformação coexistem de tal forma que torna-se difícil distinguir verdade e mentira, as diversas reviravoltas nas orientações para a prevenção e controle da COVID-19 acabaram fomentando pseudociências e fake news. ${ }^{7,8}$ Além disso, a corrida contra o tempo em busca de soluções viáveis e do desenvolvimento de vacinas permitiu o mau uso de preprints e a publicação por periódicos predatórios de trabalhos não avaliados por pares ou avaliados em um período de tempo questionável. ${ }^{8}$ Diante desse cenário, muitos pesquisadores se viram obrigados a assumir a linha de frente (redes sociais e op-eds) e contra-atacar com toda a munição disponível: conhecimento de causa e, por que não, humor. ${ }^{7}$ É preciso dizer, contudo, que a rapidez na publicação também se deu pela rapidez nas revisões por pares e pela iniciativa de alguns pesquisadores em revisar dezenas de pré-impressões bioRxiv e medRxiv, postando suas avaliações junto aos manuscritos. ${ }^{9}$ É fato: a pendemia mudou tanto a forma de fazer ${ }^{9,10}$ quanto de divulgar ciência, ${ }^{9}$ e talvez para o melhor. ${ }^{11,12}$

Está mais do que na hora, portanto, de aprimorarmos 2,13 essa troca entre usuários de informação científica, dando base, assim espera-se, ao desenvolvimento da literacia científica também fora da academia, afinal "a ciência é um bem social muito importante para permanecer confinada às paredes do laboratório". ${ }^{14}$ É essencial, para isso, que o diálogo direto com a comunidade seja mantido, pois é "quando os cientistas escrevem e compartilham seu trabalho com o público de maneiras acessíveis que a mágica acontece e podemos construir pontes entre a pesquisa e a sociedade, desenvolvendo um diálogo crítico sobre as soluções que a ciência oferece". ${ }^{13}$

\section{Referências}

1. Nogueira S. A ciência de provar qualquer coisa. Super Interessante. 2011 [atualizado 8 jan 2020; acesso 18 jan 2021]. Disponível em: https://tinyurl.com/y2xgttae

2. Biswas AK, Kirchherr J. Prof, no one is reading you. The Straits Time. 2015 [acesso 18 jan 2021]. Disponível em: https://tinyurl. com/y4wonyzb

3. Marques F. Produção científica acessível. Pesquisa. 2017;18(259):44-7. Link de acesso

4. Santos P. Desafios globais da divulgação científica. Pesquisa. 2017;18(259):87-90. Link de acesso

5. Fiske ST, Dupree C. Gaining trust as well as respect in communicating to motivated audiences about science topics. Proc Natl Acad Sci U S A. 2014;111(Suppl 4):13593-7. DOI

6. Rozières G. Coronavirus: et la science domina le débat public, pour le meilleur et pour le pire. Science. 2020 [acesso 18 jan 2021]. Disponível em: https://tinyurl.com/y3ko28gr

7. Coronavirus: face aux infox, les scientifiques s'adaptent pour contre-attaquer. 2020 [acesso 18 jan 2021]. Disponível em: https://tinyurl.com/ARCinfoCOVID

8. Scheirer W. A pandemic of bad science. Bul At Sci. 2020;76(4): 175-84. DOI

9. Callaway E. Will the pandemic permanently alter scientific publishing? Nature. 2020;582:167-8. DOI

10. Gibney E. The pandemic mixed up what scientists study and some won't go back. Nature. 2020;582:173-4. DOI 
11. Ledford $\mathrm{H}$. The coronavirus outbreak could make it quicker and easier to trial drugs. Nature. 2020;582:172. DOI

12. Mallapaty S. Scientists' worlds will shrink in the wake of the pandemic. Nature. 2020;582:169-70. DOI

13. Ngumbi E. If you want to explain your science to the public, here's some advice. Scientific American; 2018 [acesso 17 jan 2021]. Disponível em: https://tinyurl.com/EstherNgumbi

14. Scientists, keep an open line of communication with the public. Nat Med. 2020;26:1495. DOI

Rubia Carolina Farias Santos é assistente editorial das revistas Fisioterapia em Movimento e Revista Acadêmica Ciência Animal, ambas da Pontifícia Universidade Católica do Paraná (PUCPR). Curitiba, PR, Brasil.

Correspondência: rubia.farias@pucpr.br 